\title{
Interaction of Fluorescent 2-(1-Methoxynaphthalen-4-Yl)-1-(4-Methoxyphenyl)-4, 5-Diphenyl-1H-Imidazole with Pristine Zno, Cu-Doped Zno and Ag-Doped Zno Nanoparticles
}

\section{P Ponnambalam ${ }^{1}$, S Kumar ${ }^{1,2^{*}}$ and P Ramanathan ${ }^{3}$}

${ }^{1}$ Department of Chemistry, Bharathiar University, Coimbatore-641046, Tamilnadu, India

${ }^{2}$ Department of Chemistry, Thiruvalluvar College of Engineering and Technology, Tamilnadu, India

${ }^{3}$ Department of Chemistry, Thanthai Hans Roever College (Autonomous), Perambalur, Tamilnadu, India

\begin{abstract}
A sensitive 2-(1-methoxynaphthalen-4-yl)-1-(4-methoxyphenyl)-4, 5-diphenyl-1H-imidazole (MNMPI) fluorescent sensor for nanoparticulates like $\mathrm{ZnO}$, Cu-doped $\mathrm{ZnO}$ and $\mathrm{Ag}$-doped $\mathrm{ZnO}$ has been designed and synthesized. Facile preparation of $\mathrm{ZnO}$, Cu-doped $\mathrm{ZnO}$ and $\mathrm{Ag}$-doped $\mathrm{ZnO}$ nanoparticles by sol-gel method using PVP K-30 as templating agents is reported and characterised by powder X-ray diffraction (XRD), scanning electron microscopy (SEM), UVVisible spectroscopy and photoluminescence spectroscopy (PL). The synthesized sensor release is enhanced by nanocrystalline pristine $\mathrm{ZnO}$ but is suppressed by $\mathrm{Cu}$-doped $\mathrm{ZnO}$ and $\mathrm{Ag}$-doped $\mathrm{ZnO}$ nanoparticles. The suppression of fluorescence is additional by copper than by silver doping. The LUMO and HOMO energy gap of MNMPI associated with $\mathrm{Cu}$-doped $\mathrm{ZnO}$ are lowers compared to those of pristine $\mathrm{ZnO}$ and thus red shift compared to that with pristine $\mathrm{ZnO}$. The average crystallite sizes of $\mathrm{ZnO}$, Cu-doped $\mathrm{ZnO}$ and Ag-doped $\mathrm{ZnO}$ have been deduced as $32 \mathrm{~nm}, 36 \mathrm{~nm}$ and 26 $\mathrm{nm}$ and calculated surface area for $\mathrm{ZnO}$, Cu-doped $\mathrm{ZnO}$ and Ag-doped $\mathrm{ZnO}$ are $30.04 \mathrm{~m} / \mathrm{g}, 40.66 \mathrm{~m}^{2} / \mathrm{g}$ and $29.37 \mathrm{~m}^{2} / \mathrm{g}$ respectively. The observed enhanced absorbance with the distributed semiconductor nanoparticle is due to adsorption of MNMPI on semiconductor surface. This is because of the efficient transfer of electron from the excited state of the MNMPI to the conduction band of the semiconductor nanoparticle.
\end{abstract}

Keywords: MNMPI; ZnO; Cu-doped ZnO; Ag-doped ZnO; XRD; SEM; UV; PL

\section{Introduction}

The report as $\mathrm{Xia}$ is for Polymer-stabilized nano $\mathrm{ZnO}$ with blue emission [1] and the cell imaging is obtained by tunable photoluminescence with and the ZnO@polymer core-shell nanoparticles $[2,3]$. Using single crystals or polycrystalline of $\mathrm{Co}^{2+}$ : $\mathrm{ZnO}$ prepared by pellet sintering many scholars identified the observable photo response of Co-doped $\mathrm{ZnO}$. They establish that the $\mathrm{Ni}$-doped $\mathrm{ZnO}$ unfilled spheres exhibited only feeble ferromagnetism at $300 \mathrm{~K}$ whereas Co-doped $\mathrm{ZnO}$ hollow exhibited ferromagnetism at room temperature. Not due to any cobalt oxide phase formation or any metallic Co isolation the observed nature of ferromagnetism was intrinsic. Heterocyclic imidazole moieties have also attracted significant attention because of their unique optical properties [4] and for their use in preparing functionalized materials [5]. Nanoparticles can be used as drug carriers because they have enormous surface area and due to their submicron size they can efficiently be taken up by the cells [6]. $\mathrm{ZnO}$ is an attractive semiconductor material with wide direct band gap $(3.37 \mathrm{eV})$, large exciton binding energy $(60 \mathrm{meV})$ and a hexagonal structure and have significant applications in optoelectronics, sensors and actuators [7-9]. Hence, $\mathrm{ZnO}$ is one of the most attractive platforms for binding enzyme and shows potential material for a wide range of biosensor applications. $\mathrm{Au}, \mathrm{Ag}$, or Pt noble metal layered $\mathrm{ZnO}$ is significant for photoelectron transfer (PET) in the bulk and interface of $\mathrm{ZnO}$ semiconductors [10]. Under clarification of UV light, the exciton absorption bands of $\mathrm{ZnO}$ are strongly bleached due to the accumulation of conduction band electrons [11]. Thus, the effectiveness of both the photocatalysis and photoelectric energy conversion can be significantly enhanced by depositing noble metals on the surface of $\mathrm{ZnO}$ [12]. The properties and applications of noble metal $\mathrm{ZnO}$ nanostructured materials are also determined by its morphology, structure and the organization of nanostructured $\mathrm{ZnO}$ architectures [13-16]. $\mathrm{ZnO}$ based various ceramics were synthesised by liquid phase sintering of $\mathrm{ZnO}$ powder of different sizes and morphologies. The HOMO and LUMO potentials for the considered sensor must match with the conduction and valence band edges of the semiconductor nanocrystals [17].

\section{Experimental}

\section{Materials and methods}

Benzil, 4-methoxyaniline, 4-methoxynaphthaldehyde, ammonium acetate and borontrifluoride ethylethartate were purchased from Sigma Aldrich. Zinc acetate (Sd fine), polyvinylpyrrolidone (PVP K-30, Himedia), ammonia (Qualigens). The solvents used for spectral measurements were of spectroscopic grade and purchased by $\mathrm{Hi}$-media. Distilled ethanol and deionized distilled water were employed for the experiments.

Synthesis 2-(1-methoxynaphthalen-4-yl)-1-(4-methoxyphenyl)-4, 5-diphenyl-1H-imidazole

The product 2-(1-methoxynaphthalen-4-yl)-1-(4-methoxy phenyl)-4, 5-diphenyl-1H-imidazole was prepared by refluxing benzil $(1 \mathrm{mmol})$, 4-methoxyaniline $(1 \mathrm{mmol})$, 4-methoxynaphthaldehyde $(1 \mathrm{mmol})$ and ammonium acetate $(1 \mathrm{mmol})$ in ethanol $(20 \mathrm{~mL})$ for $2 \mathrm{~h}$, borontrifluoride ethylethartate ( $1 \mathrm{~mol} \%)$ acting as a catalyst (Scheme-1). The progress of the reaction was followed by TLC. After completion of the reaction, the mixture was cooled, dissolved in acetone and filtered. The product was

*Corresponding author: Kumar S, Professor and Head, Department of Chemistry, Thiruvalluvar College of Engineering and Technology, Tamilnadu, India, Tel: +918489813532; E-mail: ramanathanp2010@gmail.com

Received July 20, 2017; Accepted July 26, 2017; Published July 31, 2017

Citation: Ponnambalam P, Kumar S, Ramanathan P (2017) Interaction of Fluorescent 2-(1-Methoxynaphthalen-4-YI)-1-(4-Methoxyphenyl)-4, 5-Diphenyl$1 \mathrm{H}$-Imidazole with Pristine Zno, Cu-Doped Zno and Ag-Doped Zno Nanoparticles. Mod Chem appl 5: 226. doi: 10.4172/2329-6798.1000226

Copyright: ( 2017 Ponnambalam P, et al. This is an open-access article distributed under the terms of the Creative Commons Attribution License, which permits unrestricted use, distribution, and reproduction in any medium, provided the original author and source are credited. 
Citation: Ponnambalam P, Kumar S, Ramanathan P (2017) Interaction of Fluorescent 2-(1-Methoxynaphthalen-4-YI)-1-(4-Methoxyphenyl)-4, 5-Diphenyl-1H-Imidazole with Pristine Zno, Cu-Doped Zno and Ag-Doped Zno Nanoparticles. Mod Chem appl 5: 226. doi: 10.4172/23296798.1000226

Page 2 of 6

purified by column chromatography with benzene: ethyl acetate (9:1) as the eluent.

M.P. $296^{\circ}$ C. Anal. calcd. for $\mathrm{C}_{33} \mathrm{H}_{26} \mathrm{~N}_{2} \mathrm{O}_{2}$ : C, 82.13; H, 5.43; N, 5.81 . Found: $\mathrm{C}, 82.11 ; \mathrm{H}, 5.41 ; \mathrm{N}, 5.80 .{ }^{1} \mathrm{H}$ NMR $\left(400 \mathrm{MHz}, \mathrm{CDCl}_{3}\right): \delta 3.55(\mathrm{~s}$, $3 \mathrm{H}), 3.88(\mathrm{~s}, 3 \mathrm{H}), 6.44(\mathrm{~d}, \mathrm{~J}=8.4 \mathrm{~Hz}, 2 \mathrm{H}), 6.62(\mathrm{~d}, \mathrm{~J}=8.0 \mathrm{~Hz}, 1 \mathrm{H}), 6.73(\mathrm{~d}$, $\mathrm{J}=8.4 \mathrm{~Hz}, 2 \mathrm{H}), 7.12-7.18(\mathrm{~m}, 9 \mathrm{H}), 7.29-7.44(\mathrm{~m}, 4 \mathrm{H}), 7.82(\mathrm{dd}, \mathrm{J}=6.4 \mathrm{~Hz}$, $1 \mathrm{H}), 8.13(\mathrm{~d}, 1 \mathrm{H}) .{ }^{13} \mathrm{C} \mathrm{NMR}\left(400 \mathrm{MHz}, \mathrm{CDCl}_{3}\right): \delta 54.18,54.57,102.98$, $112.76,117.88,121.03,124.33,124.34,124.46,125.91,126.12,126.55$, $127.11,127.17,127.32,127.46,127.74,127.78,129.01,129.28,129.97$, 132.14, 132.36, 135.40, 145.36, 155.39, 157.70. MS: m/z. $482.57[\mathrm{M}+]$.

\section{Synthesis of nanocrystalline oxides by Sol-gel method}

Zinc nitrate $(0.1 \mathrm{~g})$ solution [with or without $\mathrm{Cu}\left(\mathrm{NO}_{3}\right)_{2} / \mathrm{AgNO}_{3}$ ] in $10 \mathrm{ml} 0.01 \mathrm{M}$ PVP K-30, newly prepared solution of $1: 1$ aq. $\mathrm{NH}_{3}$ was added slowly to reach a $\mathrm{pH}$ of 7 , under continuous stirring. The stirring was sustained for another $30 \mathrm{~min}$ to get a gel. The formed glassy like white gel was allowed to age overnight. It was filtered and washed with water and ethanol several times, dried at $100^{\circ} \mathrm{C}$ for $12 \mathrm{~h}$ and calcinated at $500^{\circ} \mathrm{C}$ for $3 \mathrm{~h}$ to pale grey solid.

\section{Spectral measurements}

The ${ }^{1} \mathrm{H}$ NMR and proton decoupled ${ }^{13} \mathrm{C}$ NMR spectra were recorded to using a Bruker $400 \mathrm{MHz}$ NMR spectrometer operating at $400 \mathrm{MHz}$ and $100 \mathrm{MHz}$, respectively. The UV-vis absorption and emission spectra were recorded with PerkinElmer Lambda 35 spectrophotometer and PerkinElmer LS55 spectrofluorimeter, respectively. The powder X-ray diffractogram (XRD) was recorded with a PAN analytical X'Pert PRO diffractometer using $\mathrm{Cu}$ Ka rays at $1.5406 \AA$ ' with a tube current of 30 $\mathrm{mA}$ at $40 \mathrm{kV}$. A JEOL JSM 10LV scanning electron microscope (SEM) equipped with a highly sensitive backscattered detector and low vacuum secondary detector was used to get the SEM image of the sample. The UV-vis absorption spectra were recorded with PerkinElmer Lambda 35 spectrophotometer.

\section{Results and Discussion}

\section{$\mathrm{XRD}$ analysis of $\mathrm{ZnO}$, $\mathrm{Cu}$-doped $\mathrm{ZnO}$ and $\mathrm{Ag}$-doped $\mathrm{ZnO}$ nanoparticles}

$\mathrm{X}$-ray diffraction patterns (XRD) of pristine $\mathrm{ZnO}$, Cu-doped $\mathrm{ZnO}$ and Ag-doped $\mathrm{ZnO}$ nanoparticles obtained by sol-gel method (Figure 1). All the diffraction patterns match with the JCPDS pattern of Zincite

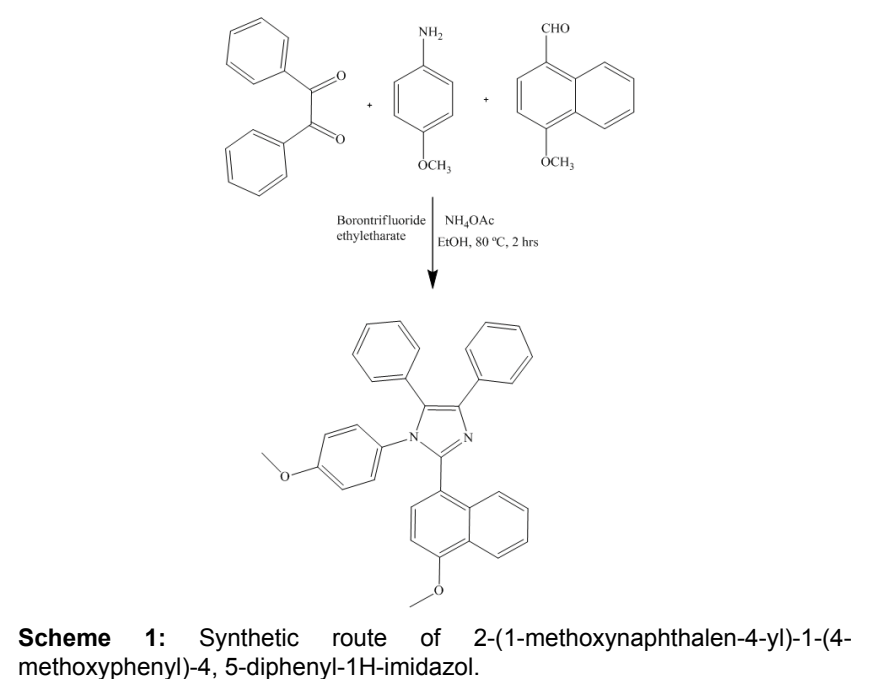

(89-7102). The crystal structures of pristine $\mathrm{ZnO}$ and doped $\mathrm{ZnO}$ are primitive hexagonal with crystal constants $a$ and $b$ as $3.249 \mathrm{~A}^{\circ}$ and $c$ as $5.025 \mathrm{~A}^{\circ}$. In the case of doping with copper, as the radii of $\mathrm{Zn}^{2+}$ and $\mathrm{Cu}^{2+}$ are comparable, $\mathrm{Cu}^{2+}$ can replace $\mathrm{Zn}^{2+}$ in the lattice without change in the lattice parameters. The XRD of $\mathrm{Ag}$-doped $\mathrm{ZnO}$ reveals the presence of metallic silver in face centered crystal lattice whereas the $\mathrm{Cu}$-doped $\mathrm{ZnO}$ fails to provide any peak other than those of $\mathrm{ZnO}$. The observed peak at $38.2^{\circ}$ is characteristic of the 111-peak of face centered cubic phase of metallic silver. The $\mathrm{Ag}^{+}$ion is better (radius $1.22 \mathrm{~A}^{\circ}$ ) than that of $\mathrm{Zn}^{2+}\left(0.72 \mathrm{~A}^{\circ}\right)$ and hence cannot be included in to the $\mathrm{ZnO}$ lattice.
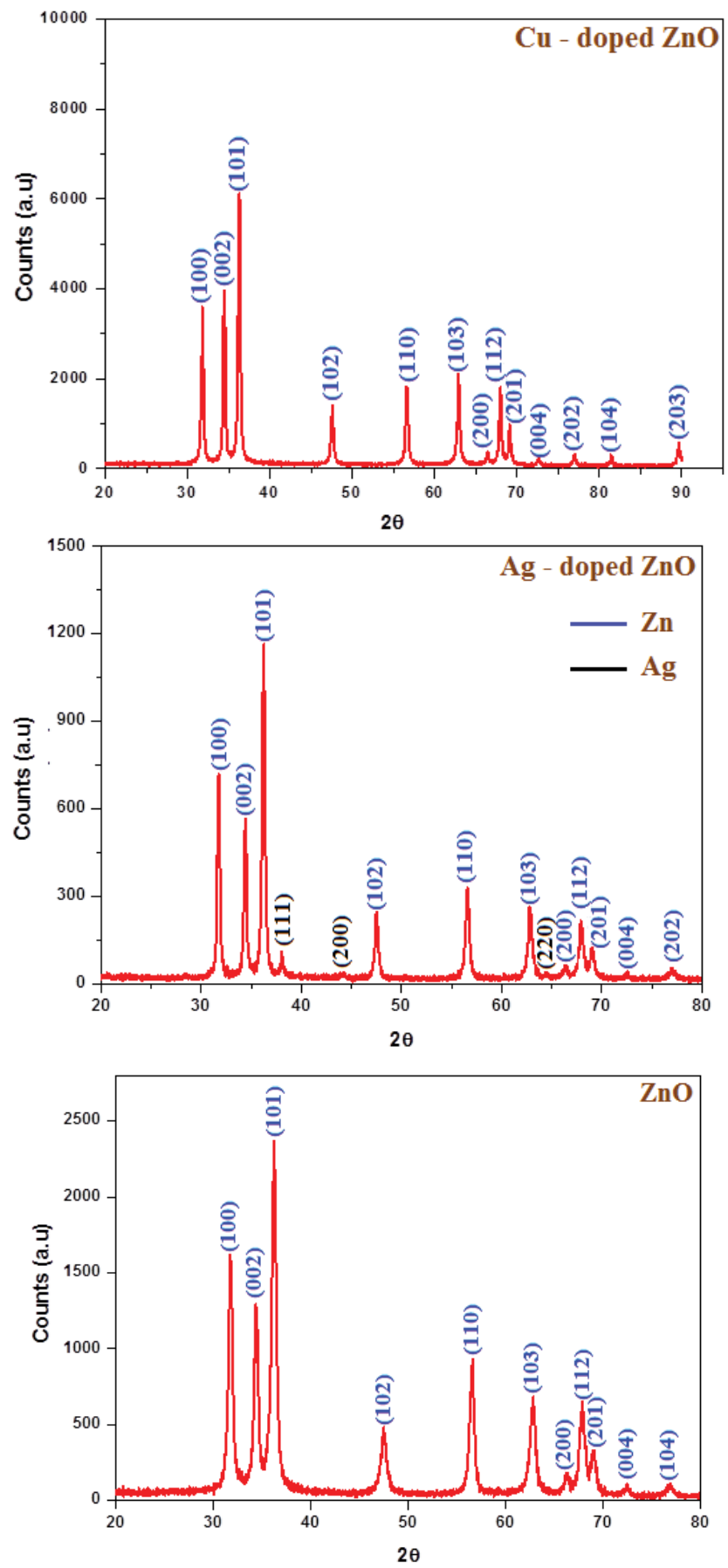

Figure 1: X-ray diffraction patterns (XRD) of pristine $\mathrm{ZnO}$, Cu-doped $\mathrm{ZnO}$ and Ag-doped $\mathrm{ZnO}$. 
Citation: Ponnambalam P, Kumar S, Ramanathan P (2017) Interaction of Fluorescent 2-(1-Methoxynaphthalen-4-YI)-1-(4-Methoxyphenyl)-4, 5-Diphenyl-1H-Imidazole with Pristine Zno, Cu-Doped Zno and Ag-Doped Zno Nanoparticles. Mod Chem appl 5: 226. doi: 10.4172/23296798.1000226

Page 3 of 6

Hence silver preferentially desire to segregate around the $\mathrm{ZnO}$ grain boundaries. The average crystallite sizes (L) of the sol-gel synthesized $\mathrm{ZnO}, \mathrm{Cu}$-doped $\mathrm{ZnO}$ and $\mathrm{Ag}$-doped $\mathrm{ZnO}$ have been deduced as 32 $\mathrm{nm}, 36 \mathrm{~nm}$ and $26 \mathrm{~nm}$, respectively. They have been obtained from the full width at half maximum (FWHM) of the most intense peaks of the individual crystals using the Scherrer equation, $\mathrm{L}=0.9 \lambda / \beta \cos \theta$, where $\lambda$ is the wavelength of the $\mathrm{X}$-rays used, $\theta$ is the diffraction angle and $\beta$ is the full width at half maximum of the peak. The calculated surface area for $\mathrm{ZnO}, \mathrm{Cu}$-doped $\mathrm{ZnO}$ and Ag-doped $\mathrm{ZnO}$ are $30.04 \mathrm{~m}^{2} / \mathrm{g}, 40.66 \mathrm{~m}^{2} / \mathrm{g}$ and $29.37 \mathrm{~m}^{2} / \mathrm{g}$, respectively.

\section{SEM and EDS analysis of $\mathrm{ZnO}, \mathrm{Cu}$-doped $\mathrm{ZnO}$, Ag-doped $\mathrm{ZnO}$ nanoparticles and imidazole- $\mathrm{ZnO}$ complex}

The SEM images of pristine $\mathrm{ZnO}, \mathrm{Cu}$-doped $\mathrm{ZnO}$ and $\mathrm{Ag}$-doped $\mathrm{ZnO}$ nanoparticles are displayed in Figure 2. The particles are flower like use of PVP as templating agent provides finite morphology. The EDS spectra are shown in Figure 3 confirm the existence of zinc, oxygen, copper and silver signals which implies the purity of the synthesized $\mathrm{ZnO}$ and $\mathrm{Cu}$-doped $\mathrm{ZnO}$ nanoparticles.

\section{Absorption and emission behaviours of imidazole with $\mathrm{ZnO}$, Cu-doped ZnO, Ag-doped ZnO nanoparticles}

The photoluminescence spectra of pristine $\mathrm{ZnO}, \mathrm{Cu}$-doped $\mathrm{ZnO}$ and Ag-doped $\mathrm{ZnO}$ nanoparticles have been recorded at room temperature. They are shown in Figure 4 . The pristine $\mathrm{ZnO}, \mathrm{Cu}$-doped $\mathrm{ZnO}$ and $\mathrm{Ag}$-doped $\mathrm{ZnO}$ nanoparticles exhibit near band gap emission (NBE) and deep level emission (DLE). The DLE arises due to different intrinsic and extrinsic structural defects in all the nanoparticles [18]. The NBE originates from the recombination of free photogenerated electrons and holes. These UV emissions concur with the absorption edges deduced from the Kubelka-Munk plots. Pristine $\mathrm{ZnO}$ display the emission around $418 \mathrm{~nm}$ was observed [19,20]. The emission originates from the electron transition from the superficial donor level of oxygen vacancies to the valence band (VB) and electron transition from the superficial donor level of zinc interstitials to the VB [21]. This emission energy corresponds to the electron change from deep-level donor of the
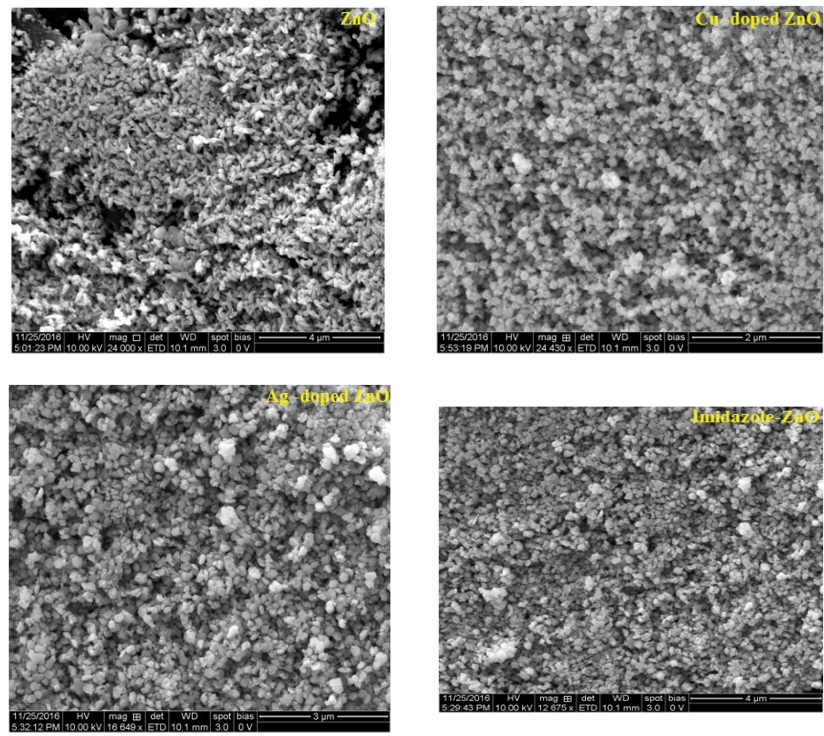

Figure 2: SEM images of pristine $\mathrm{ZnO}$, Cu-doped $\mathrm{ZnO}$, Ag-doped $\mathrm{ZnO}$ and MNMPI-ZnO. ionized oxygen vacancies to the VB. The absorption spectra of MNMPI in the existence of pristine $\mathrm{ZnO}, \mathrm{Cu}$-doped $\mathrm{ZnO}$ and $\mathrm{Ag}$-doped $\mathrm{ZnO}$ nanoparticles distributed at different loading and also in their absence are displayed in Figure 5. The nanoparticles enhance the absorbance of MNMPI remarkably. The observed enhanced absorbance with the distributed semiconductor nanoparticle is due to adsorption of MNMPI on semiconductor surface. This is because of the efficient transfer of electron from the excited state of the MNMPI to the conduction band of the semiconductor nanoparticle. The emission spectra of MNMPI in the existence of pristine $\mathrm{ZnO}, \mathrm{Cu}$-doped $\mathrm{ZnO}$ and $\mathrm{Ag}$-doped $\mathrm{ZnO}$ nanoparticles distributed at different loading and also in their absence are displayed in Figure 4. The pristine $\mathrm{ZnO}$ nanoparticle enhances the emission of MNMPI. The enhanced emission with the dispersed semiconductor nanoparticles is due to the adsorption of MNMPI on semiconductor surface. Fluorescence enhancement is due to the formation of complex [MNMPI-nanoparticulate $\mathrm{ZnO}$ ]. Doping of $\mathrm{ZnO}$ by $\mathrm{Ag}$ and $\mathrm{Cu}$ shows that the dopants inhibit the fluorescence enhancement by $\mathrm{ZnO}$. Figure 6 shows the linear variation of $\log \left[\mathrm{F}_{0}-\right.$ $\mathrm{F} / \mathrm{F}_{0}$ ] vs. [nanoparticles] and the calculated binding constant $(\mathrm{K})$ is given in Table 1 . The order of binding constant $(\mathrm{K})$ is $\mathrm{Cu}$-doped $\mathrm{ZnO}>\mathrm{ZnO}>$ Ag-doped $\mathrm{ZnO}$. The binding constant $(\mathrm{K})$ of the imidazole with $\mathrm{ZnO}$ and $\mathrm{Cu}$-doped $\mathrm{ZnO}$ are in the order of $10^{7}$ whereas that with
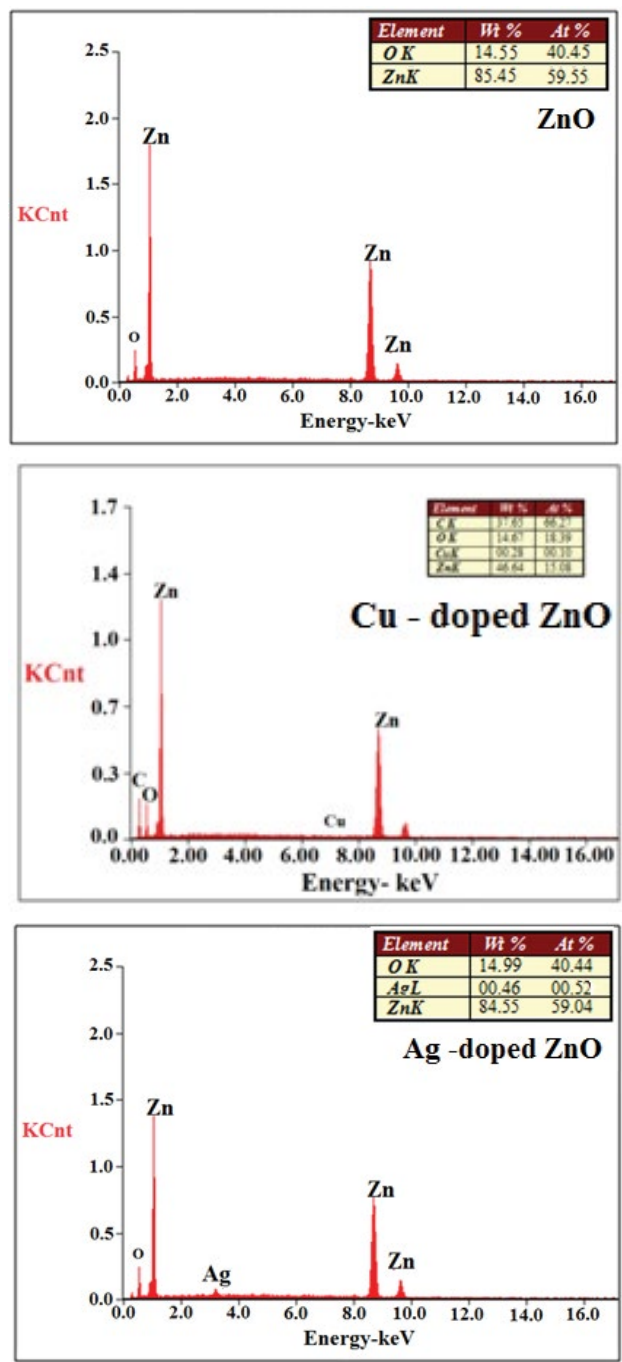

Figure 3: EDX spectra of pristine $\mathrm{ZnO}$, Cu-doped $\mathrm{ZnO}$ and Ag-doped $\mathrm{ZnO}$. 
Citation: Ponnambalam P, Kumar S, Ramanathan P (2017) Interaction of Fluorescent 2-(1-Methoxynaphthalen-4-YI)-1-(4-Methoxyphenyl)-4, 5-Diphenyl-1H-Imidazole with Pristine Zno, Cu-Doped Zno and Ag-Doped Zno Nanoparticles. Mod Chem appl 5: 226. doi: 10.4172/23296798.1000226

Page 4 of 6
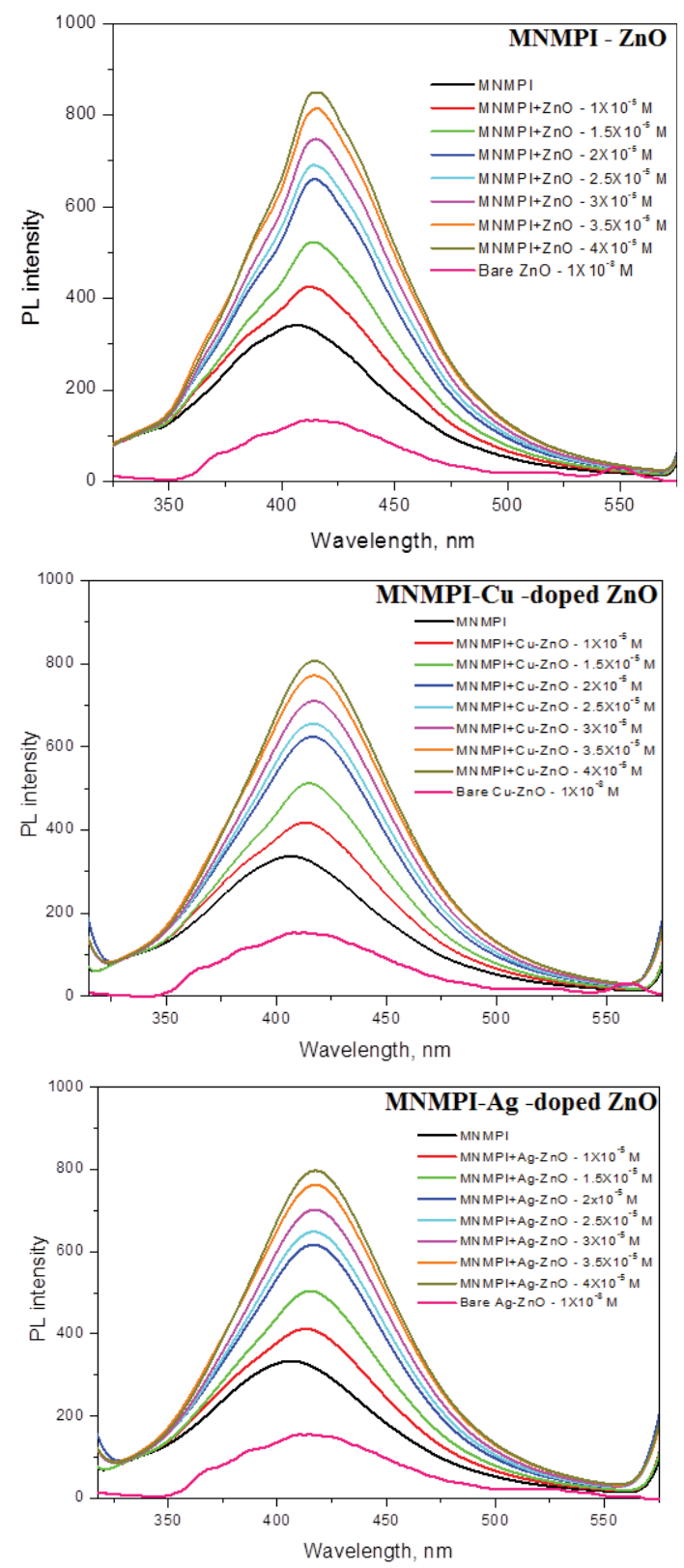

Figure 4: Emission spectra of MNMPI in presence and absence of pristine $\mathrm{ZnO}$, Cu-doped $\mathrm{ZnO}$ and Ag-doped $\mathrm{ZnO}$.

Ag-doped $\mathrm{ZnO}$ is far less. This is because in Ag-doped $\mathrm{ZnO}, \mathrm{Ag}^{0}$ is deposited on the surface of the crystal thereby inhibiting the binding of the imidazole with $\mathrm{ZnO}$. In $\mathrm{Cu}$-doped $\mathrm{ZnO}, \mathrm{Cu}^{2+}$ is likely to be present in the cationic sites or the interstitial positions thereby not influence the binding of imidazole with $\mathrm{ZnO}$. Both the dopants suppress the enhancement of fluorescence and the inhibition is more by copper than by silver doping. The possible reason is $\mathrm{Cu}^{2+}$ in $\mathrm{Cu}$-doped $\mathrm{ZnO}$ may bind with the imidazole and this binding could be much stronger than that by $\mathrm{Zn}^{2+}$. The binding of $\mathrm{Ag}$ with imidazole is not as strong as that of $\mathrm{Cu}^{2+}$ or $\mathrm{Zn}^{2+}$ and thus less binding constant.

HOMO-LUMO energy levels of imidazole with $\mathrm{ZnO}$, $\mathrm{Cu}-$ doped $\mathrm{ZnO}$, and $\mathrm{Ag}$-doped $\mathrm{ZnO}$ nanoparticles

From the onset oxidation potential $\left(\mathrm{E}_{\mathrm{o}}\right)$ and the onset reduction potential $\left(\mathrm{E}_{\text {red }}\right)$ of MNMPI derivative, HOMO and LUMO energy levels have been calculated using the equations [21], $\mathrm{HOMO}=-\mathrm{e}$ $\left(\mathrm{E}_{\mathrm{ox}}+4.71\right)(\mathrm{eV}) ; \mathrm{LUMO}=-\mathrm{e}\left(\mathrm{E}_{\mathrm{red}}+4.71\right)(\mathrm{eV})$. On the origin of the relative HOMO and LUMO energy levels of an inaccessible MNMPI molecule along with the conduction band and valence band edges of

\begin{tabular}{|c|c|c|c|c|c|}
\hline Complex & $\mathbf{~}$ & $\mathbf{k}_{\mathbf{r}}$ & $\mathbf{k}_{\mathrm{nr}}$ & $\mathbf{K}$ & $\mathbf{n}$ \\
\hline MNMPI & 3.72 & 0.80 & 1.9 & - & - \\
\hline $\begin{array}{c}\text { MNMPI... } \\
\text { ZnO }\end{array}$ & 3.33 & 0.90 & 2.1 & $2.98 \times 10^{8}$ & 0.97 \\
\hline $\begin{array}{c}\text { MNMPI... } \\
\text { Cu-ZnO }\end{array}$ & 3.21 & 0.69 & 2.6 & $9.89 \times 10^{9}$ & 0.98 \\
\hline $\begin{array}{c}\text { MNMPI... } \\
\text { Ag-ZnO }\end{array}$ & 3.42 & 0.79 & 2.2 & $9.02 \times 10^{7}$ & 0.91 \\
\hline
\end{tabular}

Table 1: Photoluminescence $(\mathrm{T}, \mathrm{ns})$, radiative $\left(\mathrm{k}_{\mathrm{r}}, 10^{8} \mathrm{~s}^{-1}\right)$, non-radiative $\left(\mathrm{k}_{n \mathrm{r}}, 10^{8} \mathrm{~s}^{-1}\right)$, binding constant $(K)$, binding sites $(n)$.
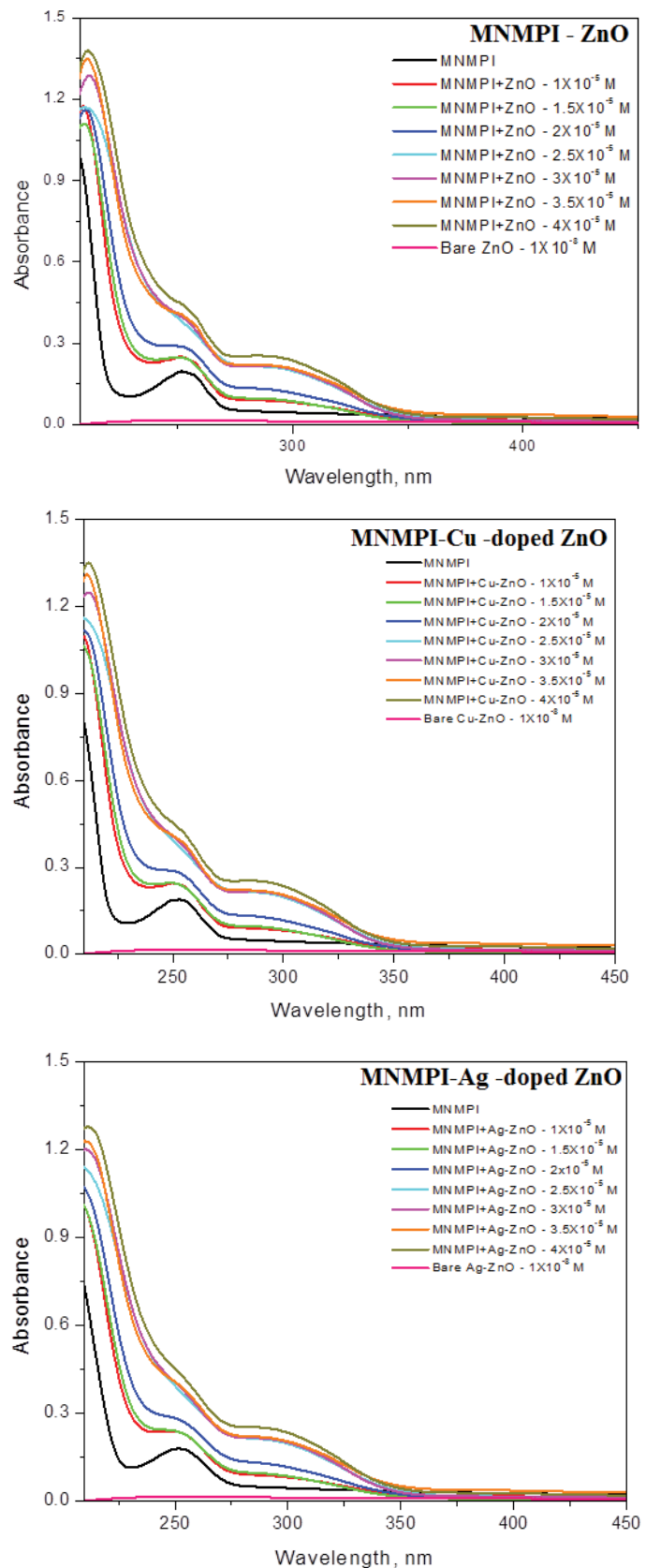

Figure 5: Absorption spectra of MNMPI in presence and absence of pristine $\mathrm{ZnO}, \mathrm{Cu}$-doped $\mathrm{ZnO}$ and Ag-doped $\mathrm{ZnO}$. 
Citation: Ponnambalam P, Kumar S, Ramanathan P (2017) Interaction of Fluorescent 2-(1-Methoxynaphthalen-4-YI)-1-(4-Methoxyphenyl)-4, 5-Diphenyl-1H-Imidazole with Pristine Zno, Cu-Doped Zno and Ag-Doped Zno Nanoparticles. Mod Chem appl 5: 226. doi: 10.4172/23296798.1000226

Page 5 of 6
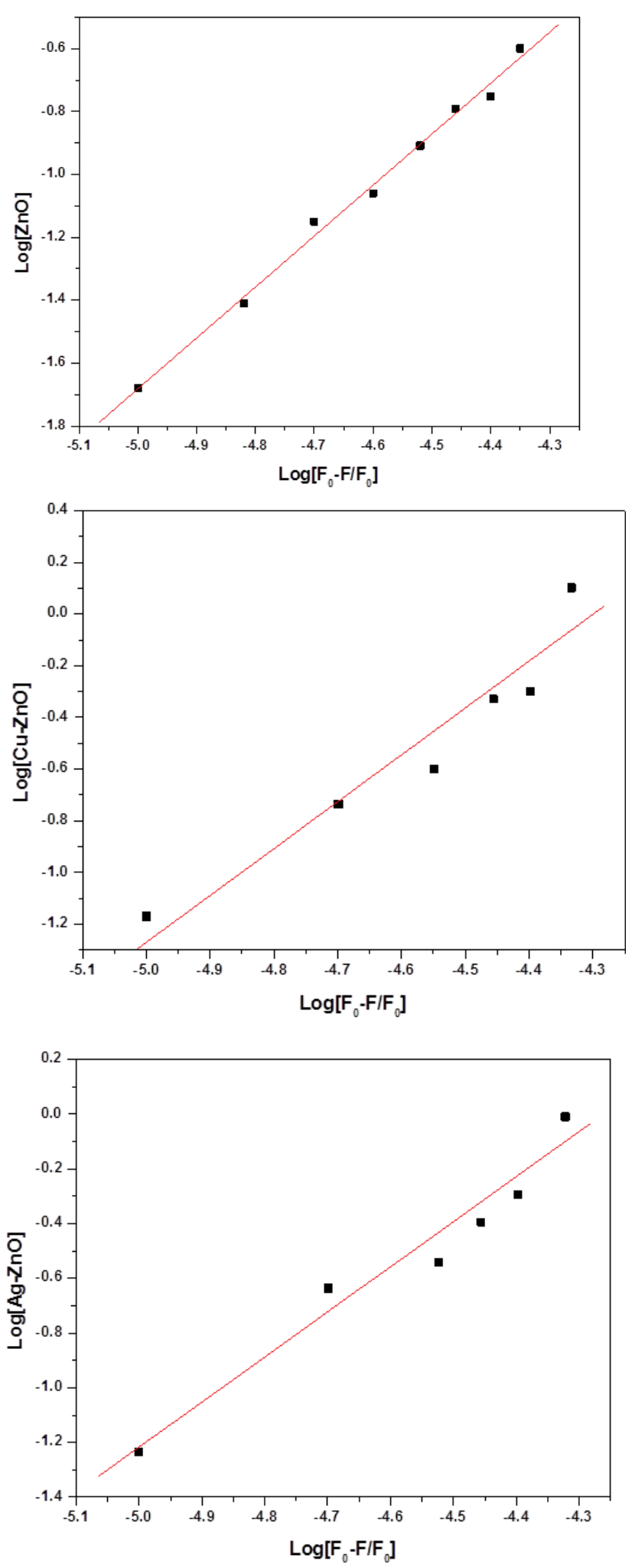

Figure 6: Stern-Volmer plot of $\log \left[\mathrm{F}_{0}-\mathrm{F} / \mathrm{F}_{0}\right]$ vs. [nanoparticles].

$\mathrm{ZnO}$ nanoparticles as shown in Figure 7, the electron injection would be thermodynamically allowed from the excited singlet of the MNMPI derivative to the conduction band of $\mathrm{ZnO}$. The energy levels presented in Figure 7 reveals the enhancement of fluorescence of MNMPI by $\mathrm{ZnO}$ nanocrystals. Electron transfer from the excited imidazole to the nanocrystals is also possible because the electron in the LUMO of the excited imidazole is of higher energy compared to that in the $\mathrm{CB}$ of $\mathrm{ZnO}$ nanocrystals [22]. This should lead to quenching of fluorescence of MNMPI. However, in differing to the expectations, enhancement of fluorescence is observed in the presence of $\mathrm{ZnO}$ nanocrystals. This may be because of lowering of the HOMO and LUMO energy levels of MNMPI due to adsorption on $\mathrm{ZnO}$ nanoparticles. The polar $\mathrm{ZnO}$ covering enhances the delocalisation of the $\pi$ electrons and lowers the HOMO and LUMO energy levels due to adsorption. The chemical

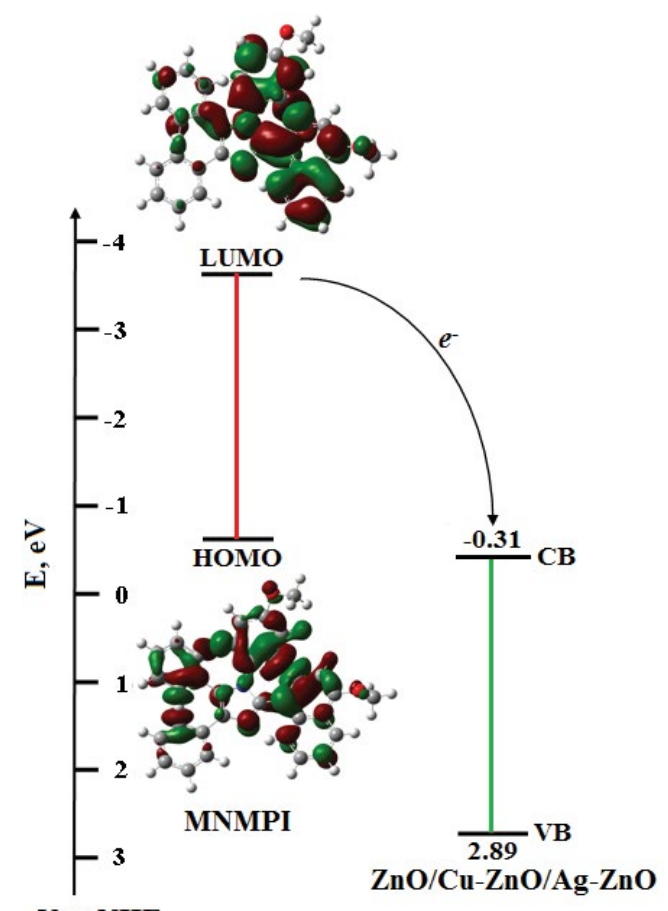

Figure 7: HOMO and LUMO energy levels of MNMPI along with the $\mathrm{CB}$ and $\mathrm{VB}$ edges of pristine $\mathrm{ZnO}$, Cu-doped $\mathrm{ZnO}$ and Ag-doped $\mathrm{ZnO}$.

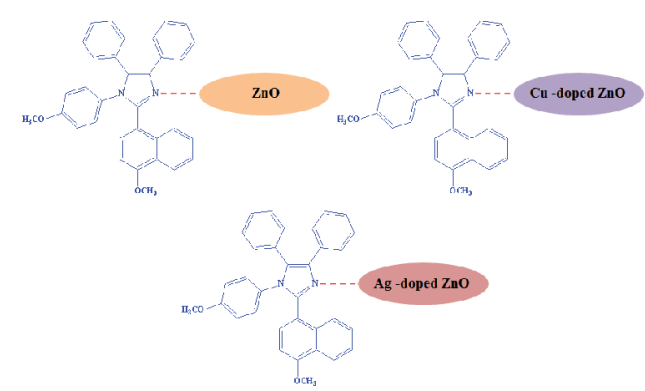

Figure 8: Schematic diagram describing the photoelectron transfer from MNMPI to nanoparticles.

affinity between the nitrogen atom of the imidazole and zinc ion on the surface of the nano-oxide may be a reason for strong adsorption of the imidazole on nanoparticle causes the enhancement.

\section{Binding interaction of imidazole with $\mathrm{ZnO}, \mathrm{Cu}$-doped $\mathrm{ZnO}$, Ag-doped ZnO nanoparticles}

The binding strength of MNMPI through its azomethine nitrogen with $\mathrm{Cu}^{2+}$ in the doped $\mathrm{ZnO}$ is likely to be stronger than that with $\mathrm{Zn}^{2+}$ in pristine $\mathrm{ZnO}$ (Figure 8). The LUMO and HOMO energy gap of 
Citation: Ponnambalam P, Kumar S, Ramanathan P (2017) Interaction of Fluorescent 2-(1-Methoxynaphthalen-4-YI)-1-(4-Methoxyphenyl)-4, 5-Diphenyl-1H-Imidazole with Pristine Zno, Cu-Doped Zno and Ag-Doped Zno Nanoparticles. Mod Chem appl 5: 226. doi: 10.4172/23296798.1000226

Page 6 of 6

MNMPI associated with $\mathrm{Cu}$-doped $\mathrm{ZnO}$ are lowers compared to those of pristine $\mathrm{ZnO}$. This inference stems from the observed red shift of the fluorescence of MNMPI on binding with $\mathrm{Cu}^{2+}$-doped $\mathrm{ZnO}$ compared to that with pristine $\mathrm{ZnO}$. The emission of MNMPI is blue shifted on association with Ag-doped $\mathrm{ZnO}$. The doped silver is likely to be present as metallic silver nano deposit on the surface of $\mathrm{ZnO}$ nanoparticles. The metallic silver on the surface of $\mathrm{ZnO}$ nanoparticles is likely to interrelate with MNMPI through its azomethine nitrogen. The interaction is likely to be weak as $\mathrm{Ag}^{0}$ is involved instead of its ionic form. The deposited silver on the surface of $\mathrm{ZnO}$ nanocrystals act as a shield making the MNMPI- $\mathrm{Zn}^{2+}$ of $\mathrm{ZnO}$ interaction less possible. The energy gap between $\mathrm{HOMO}$ and LUMO of the MNMPI-Ag-doped $\mathrm{ZnO}$ becomes larger compared to that with complex MNMPI-ZnO.

\section{Conclusion}

In conclusion, a sensitive MNMPI fluorescent sensor for nanoparticulate $\mathrm{ZnO}$ has been designed and synthesized. Facile preparation of $\mathrm{ZnO}$, Cu-doped $\mathrm{ZnO}$ and $\mathrm{Ag}$-doped $\mathrm{ZnO}$ nanoparticles by sol-gel method using PVP K-30 as templating agents is reported and characterised by X-ray diffraction, energy dispersive X-ray, UV-visible diffuse reflectance and photoluminescence spectra. MNMPI is adsorbed on the surface of semiconductor nanoparticle during azomethine nitrogen. The polar $\mathrm{ZnO}$ surface enhances the delocalisation of the $\pi$ electrons and lowers the HOMO and LUMO energy levels due to adsorption. The LUMO and HOMO energy gap of MNMPI associated with $\mathrm{Cu}$-doped $\mathrm{ZnO}$ are lowers compared to those of pristine $\mathrm{ZnO}$ and thus red shift compared to that with pristine $\mathrm{ZnO}$. The energy gap between HOMO and LUMO of the complex MNMPI-Ag-doped ZnO becomes larger compared to that with complex MNMPI-ZnO and the emission compared to those of pristine $\mathrm{ZnO}$. The conduction band energy position determines the electron transfer from excited state MNMPI to the $\mathrm{ZnO}, \mathrm{Cu}$-doped $\mathrm{ZnO}$ and $\mathrm{Ag}$-doped $\mathrm{ZnO}$ nanoparticles.

\section{Acknowledgments}

The authors are very thankful to guide Dr. S. Kumar, Professor and Head, Department of Chemistry, Thiruvalluvar College of Engineering and Technology, Vandavasi for moral support in my studies. Instrumentation facilities are will be provided by Department of Chemistry, Annamalai University, Annamalainagar, Chidambaram.

\section{References}

1. Xiong HM, Wang ZD, Xia YY (2006) Polymerization initiated by inherent free radicals on nanoparticle surfaces: A Simple method of obtaining ultrastable $(\mathrm{ZnO})$ polymer core-shell nanoparticles with strong blue fluorescence. Adv Mater 18: 748-751.

2. Xiong HM, Xu Y, Ren QG, Xia YY (2008) Stable aqueous ZnO@polymer coreshell nanoparticles with tunable photoluminescence and their application in cell imaging. J Am Chem Soc 130: 7522-7523.

3. Subramanian V, Wolf EE, Kamat PV (2003) Green emission to probe photoinduced charging events in $\mathrm{ZnO}-\mathrm{Au}$ nanoparticles. Charge distribution and Fermi-level equilibration. J Phys Chem B 107: 7479-7485.

4. Hung WS, Lin JT, Chien CH, Tao T, Sun SS, et al. (2004) Highly phosphorescent bis-cyclometalated iridium complexes containing benzoimidazole-based ligands. Chem Mater 16: 2480-2488.
5. Nakashima K (2003) Lophine derivatives as versatile analytical tools. Biomed Chromatogr 17: 83-95.

6. Wiseman A (1985) Handbook of Enzyme Biotechnology, Horwoodi, Chichester

7. Masuda Y, Kato K (2008) High c-axis oriented stand-alone $\mathrm{ZnO}$ self-assembled film. Crystal Growth and Design 8: 275-279.

8. Zhang XM, Lu MY, Zhang Y, Chen LJ, Wang ZL, et al. (2009) Fabrication of a high-brightness blue-light-emitting diode using a $\mathrm{ZnO}$-nanowire array grown on p-GaN thin film. Adv Mater 21: 2767-2770.

9. Topoglidis E, Cass AEG, Regan BO, Durrant JR (2001) Immobilisation and bioelectrochemistry of proteins on nanoporous $\mathrm{TiO}_{2}$ and $\mathrm{ZnO}$ films. J Electroanal Chem 517: 20-27.

10. Chen S, Ingram RS, Hostetler MJ, Pietron JJ (1998) Gold nanoelectrodes of varied size: Transition to molecule-like charging. Science 280: 2098-2101.

11. Ozgur U, Alivov I, Liu C, Teke A (2005) A comprehensive review of ZnO materials and devices. J Appl Phys 98: pp:041301.

12. Huang MH, Mao S, Feick H, Yan HQ (2001) Room-temperature ultraviolet nanowire nanolasers. Science 292: 1897-1899.

13. Wang YW, Zhang LD, Wang GZ (2002) Catalytic growth of semiconducting zinc oxide nanowires and their photoluminescence properties. J Cryst Growth 234: 171-175.

14. Feng X, Feng L, Jin M, Zhai J (2004) Reversible super-hydrophobicity to superhydrophilicity transition of aligned $\mathrm{ZnO}$ nanorod films. J Am Chem Soc 126 : 62-63.

15. Law M, Greene LE, Jhonson JC (2005) Nanowire dye-sensitized solar cells Nat Mater 4: 455-459.

16. Karunakaran C, Jayabharathi J, Kalaiarasi V, Jayamoorthy K (2014) Characterization and electronic spectral studies of 2-(naphthalen-1-yl)-4,5diphenyl-1H-imidazole bound $\mathrm{Fe}_{2} \mathrm{O}_{3}$ nanoparticles. Spectrochimica Acta Part A 120: 84-87.

17. Wang X, Zhang Q, Wan Q, Dai G (2011) Controllable ZnO architectures by ethanolamine-assisted hydrothermal reaction for enhanced photocatalytic activity. J Phys Chem C 115: 2769-2775.

18. Becker J, Raghupathi KR, Pierre J (2011) Tuning of the crystallite and particle sizes of $\mathrm{ZnO}$ nanocrystalline materials in solvothermal synthesis and their photocatalytic activity for dye degradation. J Phys Chem C 115: 13844-13850.

19. Jing L, Qu Y, Wang B, Li S (2006) Review of photoluminescence performance of nano-sized semiconductor materials and its relationships with photocatalytic activity. J Sun Sol Energy Mater Sol Cells 90: 1773-1787.

20. Hou J, Huo L, He C, Yang C (2006) Synthesis and absorption spectra of Poly (3-(phenylenevinyl) thiophene)s with conjugated side chains. Macromolecules 39: 594-603.

21. He WY, Li Y, Xue C, Hu ZD (2005) Effect of Chinese medicine alpinetin on the structure of human serum albumin. Bioorg Med Chem 13: 1837-1845.

22. Kavarnos GJ, Turro N (1986) Photosensitization by reversible electron transfer: Theories, experimental evidence, and examples. Chem Rev 86: 401-449. 